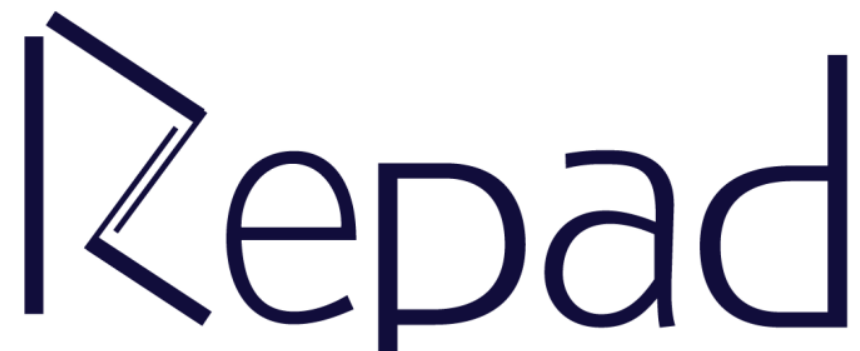

Vol. 1, N. 1 Dezembro/2017

Revista Estudos e

Pesquisas em Administração

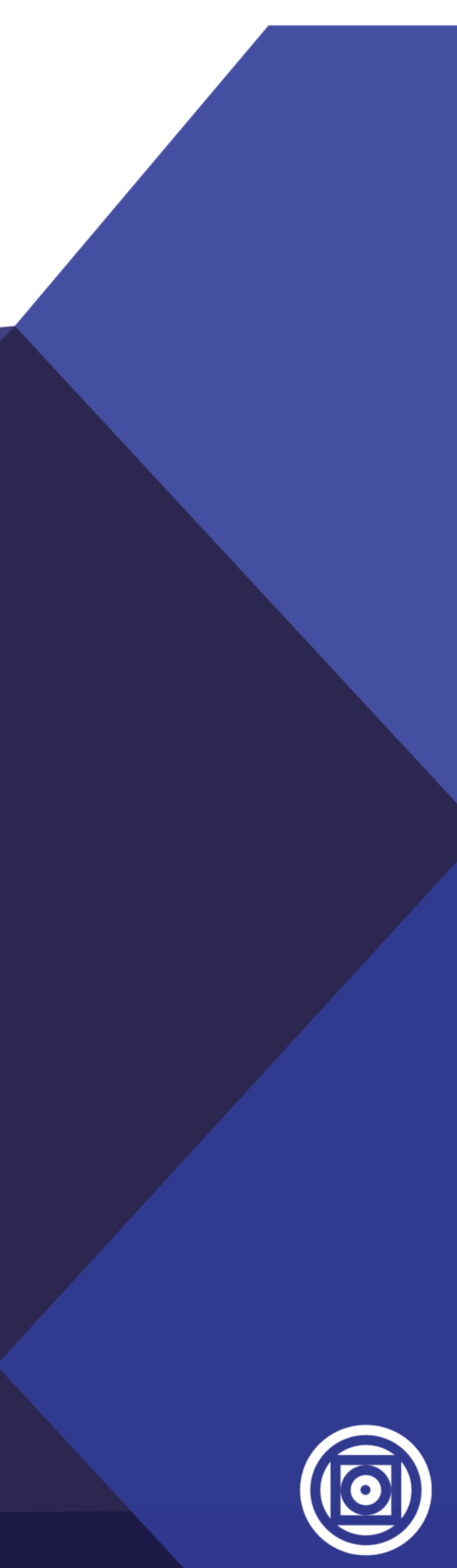




\title{
ÍNDICE DE DESENVOLVIMENTO SUSTENTÁVEL DE PRIMAVERA DO LESTE - MT, BASEADO NO MODELO DE MARTINS E CÂNDIDO (2008)
}

\author{
Greyce Bernardes de Mello Rezende \\ Professora da Universidade Federal de Mato Grosso, campus universitário do Araguaia \\ http://orcid.org/0000-0002-2023-2015 \\ Eliane Aparecida Antunes Fagundes \\ Universidade Federal de Mato Grosso
}

\section{RESUMO}

Para que um município seja considerado sustentável, deve evitar a degradação do seu sistema ambiental, reduzir as desigualdades sociais e propiciar a seus habitantes um ambiente saudável e seguro. Portanto, as medidas mais apropriadas para a sustentabilidade local estão relacionadas às políticas públicas visando a integração das dimensões social, ambiental, econômica e institucional, mas também da participação da população nesse processo. Nessa perspectiva, essa pesquisa, desenvolvida de forma quantitativa, exploratória e descritiva, teve como objetivo mensurar o grau de sustentabilidade de Primavera do Leste - MT, mediante aplicação da metodologia do Índice de Desenvolvimento Sustentável para Municípios (IDSM). No tocante aos resultados, Primavera do Leste apresenta um IDSM de 0,6155, que é um índice com desempenho aceitável, conforme os parâmetros utilizados na metodologia. Contudo, mesmo que os resultados apresentados não sejam críticos, é necessário que políticas públicas sejam implementadas, levando em consideração os indicadores que apresentaram níveis mais baixos, para melhorar ainda mais a qualidade de vida dos munícipes.

Palavras-chave: Desenvolvimento Sustentável Local, Indicadores, Índice De Desenvolvimento Sustentável Para Municípios (IDSM).

\section{SUSTAINABLE DEVELOPMENT INDEX OF PRIMAVERA DO LESTE-MT, BASED ON MARTINS AND CÂNDIDO'S MODEL (2008)}

\begin{abstract}
In order for a municipality to be sustainable, it needs to avoid degradation of the environment, reduce social inequalities and provide the inhabitants with a healthy and safe environment. Therefore, the most appropriate measures for local sustainability are related to public policies aiming at the integration of social, environmental, economic and institutional dimensions. In addition, the population must participate in this process. In this perspective, this quantitative, exploratory and descriptive research aimed to verify the degree of sustainability of Primavera do Leste - MT, using the Index of Sustainable Development for Municipalities (IDSM). Regarding the results, Primavera do Leste has an IDSM of 0,6155, which is an acceptable index to parameters used in the methodology. However, even though the results found are not critical, it is necessary that actions be implemented, taking into account the indicators that presented lower levels, to further improve residents' quality of life.
\end{abstract}

Keywords: Local Sustainable Development, Indicators, Index of Sustainable Development for Municipalities. 


\section{INTRODUÇÃO}

Nos dias atuais, onde se observa preponderância do consumismo e individualismo atrelado ao desenvolvimento das nações, é de salutar importância que gradativamente os atores sociais se conscientizem de que estamos nos encaminhando para um patamar onde a degradação do meio ambiente pode se tornar irreversível.

Por esse motivo, deve-se percorrer um caminho em direção ao desenvolvimento de forma sustentável, onde a responsabilidade na preservação do meio ambiente deve ser atribuída a todos; ou seja, não basta à implementação de políticas públicas de preservação, se o cidadão também não adotar práticas sustentáveis.

Dessa forma, para uma aplicação efetiva do conceito de desenvolvimento sustentável, foi desenvolvida a metodologia de indicadores de sustentabilidade, a qual é aplicada mediante a comparação e exame de características e políticas públicas implementadas em cidades e regiões, a fim de avaliar o grau de sustentabilidade no desenvolvimento daquela localidade. Com essa providência, é possível sinalizar quais índices são positivos e quais necessitam de medidas proativas e reativas a serem adotadas, antes que danos irreversíveis possam ocorrer.

No contexto municipal, a utilização dos indicadores pelos gestores públicos é muito relevante para demonstrar as intervenções necessárias a fim de corrigir discrepâncias encontradas, viabilizando o desenvolvimento sustentável local, e consequentemente regional, atingindo então um grau de sustentabilidade efetiva.

A metodologia desenvolvida por Martins e Cândido (2008) é capaz de aferir o índice de desenvolvimento sustentável de determinado município. Essa metodologia é integrada pelo conjunto de seis dimensões (social, demográfica, ambiental, econômica, político-institucional e cultural), cada qual com seus respectivos indicadores.

Em face do exposto, o objetivo da presente pesquisa é mensurar o grau de sustentabilidade do município de Primavera do Leste - MT, aplicando-se como instrumento de trabalho o Índice de Desenvolvimento Sustentável para Municípios (IDSM).

O Município de Primavera do Leste - MT foi escolhido para ser objeto desta pesquisa, em razão de não terem sido localizados prévios estudos científicos que tratem da sustentabilidade desse município, considerando a aplicação da metodologia de indicadores. Além disso, Primavera do Leste - MT possui grande importância regional, uma vez que é uma das cidades que mais se desenvolve no sudeste do Estado, além de exercer um papel importante no agronegócio.

Nesse contexto, ressalta-se ainda que, para comparação de valores e construção dos índices, foram escolhidos outros quatro municípios. O fator determinante para a escolha desses municípios foram as características semelhantes a Primavera do Leste, dentre eles a quantidade populacional; outrossim, ambos pertencem a cada uma das mesorregiões do Estado de Mato Grosso, de forma possibilitar a comparação de dados de diversas localidades.

\section{REFERENCIAL TEÓRICO}

Nesta seção, são apresentados os conceitos ou termos básicos para a realização do estudo sobre a sustentabilidade do município de Primavera do Leste, a partir do suporte teórico de alguns autores. Dentre os conceitos principais deste estudo, merecem destaques: desenvolvimento sustentável, sistemas de indicadores e Índice de Desenvolvimento Sustentável para Municípios. 


\section{DESENVOLVIMENTO SUSTENTÁVEL}

Um dos documentos mais importantes sobre desenvolvimento sustentável foi o Relatório Brundtland, publicado em 1987 (CMMAD, 1991), pois foi um marco no tocante a visão crítica do modelo de desenvolvimento, trazendo para o debate a noção de desenvolvimento sustentável. Sua importância foi tamanha que o conceito foi colocado diretamente em discussão na Cúpula da Terra, realizada no Rio de Janeiro em 1992.

A definição de desenvolvimento sustentável, difundida pelo Relatório Brundtland, como "aquele que atende às necessidades do presente sem comprometer a capacidade de as futuras gerações atenderem também as suas" (CMMAD, 1991, p. 9) contém a ideia de necessidade e limite. Para Cavalcanti (2003), é cada vez mais generalizada, atualmente, a consciência do dever para com as necessidades das gerações futuras e os limites que a natureza e o meio ambiente impõem. Com certeza, intui-se que a base física da qual se retira o sustento do homem não pode ser sobrecarregada impune e indefinidamente.

Cavalcanti (2003) é categórico ao afirmar que, com o conhecimento científico disponível, é impossível entender a verdadeira natureza do desejo moderno do homem na busca pelo desenvolvimento econômico. Esse desenvolvimento, sob a forma como é compreendido, frequentemente conduz a algum tipo de agressão contra o meio ambiente, com o consequente esgotamento de alguma categoria de recursos não renováveis.

Nesse contexto, a ideia do desenvolvimento ligada estritamente ao crescimento econômico, precisa ser substituída pela compreensão de desenvolvimento sustentável, a partir da incorporação e da busca do equilíbrio entre as dimensões social, institucional, econômica e ambiental. (SANTOS; CÂNDIDO, 2010).

Para Cândido (2004), essa mudança de enfoque está centrada na premissa de que, sem atingir certo nível de desenvolvimento social, as sociedades terão grandes dificuldades para se expandir economicamente, ou seja, o capital econômico não consegue se acumular e reproduzir sustentavelmente onde não exista um conjunto de outras dimensões, baseadas em aspectos sociais, políticas institucionais e ambientais.

Já Guimarães (2010) afirma que se deve operacionalizar o desenvolvimento, de forma a estabelecer parâmetros de avaliação, a partir dos critérios definidos como caracterizadores do desenvolvimento e da sustentabilidade. Tais parâmetros estarão conformados com determinada perspectiva teórica interpretativa e têm o mérito de possibilitar a análise objetiva de processos de desenvolvimento sustentável.

Em vista do exposto, verifica-se que os indicadores de sustentabilidade possuem grande relevância para o monitoramento de um processo de desenvolvimento em bases sustentáveis, por meio da operacionalização de um conjunto de critérios denominados variáveis, importantes para a compreensão da realidade investigada.

\section{SISTEMAS DE INDICADORES}

Segundo Cândido e Vasconcelos (2011), os conceitos e abordagens que permeiam as questões relacionadas ao desenvolvimento sustentável são inúmeros, assim como são as iniciativas por parte de pesquisadores e organizações que buscam uma forma sintética de mensurá-lo através de indicadores.

Considerando que o mecanismo de desenvolvimento não é estático e, portanto, de mudança contínua, é necessário que os sistemas de monitoramento captem periodicamente os resultados desse desenvolvimento, detectando vulnerabilidades de formas pontuais, bem como demais aspectos que mereçam análises mais específicas. 
É nesse contexto que os indicadores são utilizados, pois seu objetivo é sintetizar informações periódicas de forma efetiva e significativa, melhorando o processo de comunicação. Isso é de fundamental importância para a tomada de decisões e a implementação de políticas públicas mais eficazes.

Sobre esse item, é importante também diferenciar duas nomenclaturas distintas, a saber: índices e indicadores, pois frequentemente ocorrem confusões acerca das mesmas. Para tanto, Siche et al. (2007) distinguem os dois termos da seguinte forma: o primeiro sendo um valor numérico que representa a correta interpretação da realidade de um sistema simples ou complexo (natural, econômico ou social), utilizando, em seu cálculo, bases científicas e métodos adequados. Já o segundo é entendido como um parâmetro selecionado, considerado isoladamente ou em combinação com outros, para refletir sobre as condições do sistema em análise. Para exemplificar, cita-se a composição do Índice de Desenvolvimento Humano (IDH), onde verifica-se a presença de indicadores como renda, saúde e expectativa de vida.

Assim sendo, diversos tipos de sistemas têm sido utilizados para mensurar o processo de desenvolvimento sustentável de localidades ou nações. De acordo com Van Bellen (2005), os sistemas de indicadores mais reconhecidos são: Pegada Ecológica (Ecological Footprint Method), desenvolvida por Wackernagel and Rees; o Painel da sustentabilidade (Dashboard of Sustainability), desenvolvido pelo Instituto Internacional para o Desenvolvimento Sustentável e o Barômetro da Sustentabilidade (Barometer of Sustainability), desenvolvido por diversos especialistas ligados ao Instituto World Conservation Union (IUCN).

Importante destacar que, alguns índices de mensuração da sustentabilidade têm alcançado respaldo internacional, político e científico, como: Índice de Desenvolvimento Econômico Sustentável (IDES), Índice de Bem-Estar Econômico Sustentável (IBES) e o Índice de Progresso Genuíno (IPG).

No Brasil, destaca-se a metodologia do Índice de Desenvolvimento Sustentável (IDS), desenvolvida pelo IBGE (2012) e inspirada em recomendações feitas pela Comissão para o Desenvolvimento Sustentável (CDS) das Nações Unidas. Tal metodologia é aplicada em dimensões estaduais.

Em face do exposto, verifica-se que há uma significativa quantidade de sistemas de indicadores, porém, em razão do recorte geográfico ser direcionado para países e estados, surge uma carência em relação aos estudos de indicadores e índices que considerem dimensões territoriais e escalas menores de avaliação da sustentabilidade, como por exemplo a municipal. Dentro dessa contextualização, encontra-se o Índice de Desenvolvimento Sustentável para Municípios (IDSM), que operacionaliza a questão do desenvolvimento sustentável, por meio da ação local, como propõem Martins e Cândido (2008).

\section{PROCEDIMENTOS METODOLÓGICOS}

\section{CLASSIFICAÇÃO DA PESQUISA}

Este estudo, quantitativo, descritivo e exploratório, tem o objetivo de mensurar o desempenho do município de Primavera do Leste em relação ao desenvolvimento local sustentável, adotando os procedimentos metodológicos do IDSM.

Trata-se de pesquisa quantitativa uma vez que nela foi utilizado o levantamento de dados quantitativos, disponibilizados por institutos de pesquisa e obtidos junto a órgãos públicos e instituições.

O estudo também pode ser classificado, quanto a seus objetivos, em pesquisa descritiva, tendo em vista à necessidade de descrição de uma realidade por meio de um conjunto de indicadores de sustentabilidade. Por fim, entende-se ainda como pesquisa exploratória, devido 
ao caráter recente e pouco explorado do tema, notadamente no tocante à seleção dos indicadores para desenvolvimento sustentável municipal. (MARTINS; CÂNDIDO, 2008)

\section{MÉTODO DE PESQUISA}

O Índice de Desenvolvimento Sustentável para Municípios (IDSM) é um método criado por Martins e Cândido (2008) que consiste em um sistema de indicadores, pelo qual os municípios são avaliados segundo seu nível de desenvolvimento sustentável. Esse método foi elaborado para suprir a carência de dados específicos para municípios, uma vez que os demais instrumentos se referem a estados ou países. O diferencial do IDSM é sua aplicação em âmbito municipal, por meio de 54 indicadores de sustentabilidade, dentro de seis dimensões: ambiental, econômica, social, institucional, demográfica e cultural, como demonstrado no Quadro 01.

Quadro 01: Dimensões e indicadores do IDSM

\begin{tabular}{|c|c|}
\hline DIMENSÃO SOCIAL & DIMENSÃO DEMOGRÁFICA \\
\hline Esperança de vida ao nascer & Crescimento da população \\
\hline Taxa de Mortalidade Infantil & Razão entre a população urbana e rural \\
\hline Prevalência da desnutrição total & Densidade demográfica \\
\hline Imunização contra doenças infecciosas infantis & Razão entre a população masculina e feminina \\
\hline Oferta de Serviços básicos de saúde & Distribuição da População por faixa etária \\
\hline \multicolumn{2}{|l|}{ Taxa de Escolarização } \\
\hline Taxa de alfabetização & DIMENSÃO ECONÔMICA \\
\hline Escolaridade & Produto Interno Bruto per capita \\
\hline Analfabetismo funcional & Participação da Indústria no PIB \\
\hline Familias atendidas com programas sociais & Saldo da balança comercial \\
\hline Adequação de moradia nos domicílios & Renda Familiar per capita em salários mínimos \\
\hline Mortalidade por homicídio & Renda per capita \\
\hline Mortalidade por acidente de transporte & Rendimentos provenientes do trabalho \\
\hline & Índice de Gini de distribuição do rendimento \\
\hline DIMENSÃO POLÍTICO-INSTITUCIONAL & DIMENSÃO AMB IENTAL \\
\hline Despesas com Assistência Social, & $\begin{array}{l}\text { Qualidade das águas: Aferição de Cloro residual, de } \\
\text { Turbidez, de Coliformes fecais }\end{array}$ \\
\hline Despesas com Educação & Tratamento das águas: tratadas em ETAs \\
\hline Despesas com Cultura & Tratamento das águas: tratadas por desinfecção \\
\hline Despesas com Urbanismo & Consumo Médio per capita de água \\
\hline Despesas com Habitação Urbana & Acesso ao sistema de abastecimento de água \\
\hline Despesas com Gestão Ambiental & Tipo de esgotamento sanitário por domicîlio \\
\hline Despesas com Ciência e Tecnologia & Acesso à coleta de Lixo urbano e rural \\
\hline Despesas com Desporte e Lazer & DIMENSÃO CULTURAL \\
\hline Despesas com Saneamento Urbano & Quantidade de Bibliotecas \\
\hline Despesas com Saúde & Quantidade de Museus \\
\hline Acesso a Serviço de Telefonia Fixa & Quantidade de Ginásios de esportes e estádios \\
\hline Participação nas Eleições & Quantidade de Cinemas \\
\hline Número de Conselhos Municipais & Quantidade de Unidades de ensino superior \\
\hline Número de Acessos a Justiça & Quantidade de teatros ou salas de espetáculos \\
\hline Transferências Intergovernamentais da União & Quantidade de Centros cultural \\
\hline
\end{tabular}

Fonte: Adaptado de Martins e Cândido (2008).

Portanto, conforme relatado será utilizado neste estudo o Índice de Desenvolvimento Sustentável para Municípios criado por Martins e Cândido (2008), o qual surgiu a partir da 
junção de duas outras ferramentas: O Índice de Desenvolvimento Sustentável - IDS Brasil e o Índice de Desenvolvimento Sustentável para Territórios Rurais, tornando-se uma ferramenta aplicada à realidade dos municípios.

Algumas variáveis da metodologia do IDSM, visualizadas no Quadro 01, sofreram alteração em virtude de melhor adequação à área de estudo, bem como disponibilidade de dados. O Quadro 02 apresenta a relação dos indicadores que sofreram alteração, todos relativos à dimensão social.

Quadro 02: relação de indicadores alterados na dimensão social

\begin{tabular}{|ll|}
\hline \multicolumn{1}{|c|}{ Dimensão Social } \\
Indicadores iniciais & Indicadores alterados \\
Taxa de escolarização de 0 a 6 anos & Taxa de escolarização de 4 a 5 anos \\
Taxa de escolarização de 7 a 14 anos & Taxa de escolarização de 6 a 14 anos \\
Taxa de escolarização de 25 anos ou mais & Taxa de escolarização de 25 anos a 29 anos \\
Escolaridade & Expectativa de anos de estudo \\
Taxa de analfabetismo funcional & Taxa de analfabetismo \\
Coeficiente de mortalidade por homicídios & Coeficiente de mortalidade por agressões \\
\hline
\end{tabular}

Fonte: A pesquisa (2017)

Na dimensão ambiental, nos aspectos referentes ao acesso ao sistema de abastecimento de água, de esgotamento sanitário e de serviços de coleta de lixo, os dados coletados referem-se conjuntamente a área urbana e rural, o que difere da metodologia de Martins e Cândido (2008) que apresentam estes dados separados.

\section{COLETA DE DADOS}

Para esta pesquisa os dados e informações foram coletados por meio de dados secundários, disponibilizados nos principais institutos de pesquisas e órgãos governamentais, acessíveis nos sites do Atlas de Desenvolvimento Humano (2013), Caderno de Informações de Saúde do Departamento de Informática do Sistema Único de Saúde do Brasil (2014), Instituto Brasileiro de Geografia e Estatística - IBGE (2010), Caixa Econômica Federal - CEF (2014), Secretaria do Comércio Exterior - Secex (2014), Finanças do Brasil - Finbra (2014), Agência Nacional de Telecomunicações - Anatel (2014), Tribunal Superior Eleitoral - TSE (2012) e Sistema Nacional de Informações sobre Saneamento - SNIS (2014).

\section{TÉCNICA DE ANÁLISE DE DADOS}

Quanto aos procedimentos metodológicos adotados por Martins e Cândido (2008), a seguinte sequência deve ser observada:

a) Após a escolha do conjunto de variáveis, observa-se que estas apresentam diferentes unidades de medida. No intuito de facilitar a análise, elas são transformadas em índices que possibilitam a agregação nas respectivas dimensões para a estimação do IDSM.

b) É preciso classificar essas variáveis quanto a sua Relação Positiva ou Negativa no tocante ao desenvolvimento sustentável: I) Relação Positiva, quando verificado que, quanto maior o indicador melhor será índice; e quanto menor o indicador pior será o índice. II) Relação Negativa, quando verificado que, quanto maior o indicador pior será o índice; e quanto menor o indicador, melhor será o índice. 
c) Após identificar a relação positiva ou negativa da variável com o processo de desenvolvimento sustentável, é feita a operacionalização para o cálculo do índice, a partir de fórmulas que reconhecem essas relações e permitem a análise da sustentabilidade, através da agregação de todos os índices.

As fórmulas utilizadas para a geração dos índices de sustentabilidade podem ser visualizadas na Quadro 02.

Quadro 03: fórmula dos índices conforme o tipo de relação (positiva ou negativa)

\begin{tabular}{|cc|}
\hline Quando a relação é positiva: & Quando a relação é negativa: \\
\hline $\mathrm{I}=\frac{(\mathrm{x}-\mathrm{m})}{(\mathrm{M}-\mathrm{m})}$ & $\mathrm{I}=\frac{(\mathrm{M}-\mathrm{x})}{(\mathrm{M}-\mathrm{m})}$ \\
\hline
\end{tabular}

Fonte: Adaptado de Martins e Cândido (2008).

Referência:

$\mathrm{I}$ = índice calculado para cada território analisado;

$\mathrm{x}=$ valor observado de cada variável em cada território analisado;

$\mathrm{m}=$ valor mínimo considerado;

$\mathrm{M}=$ valor máximo considerado

Para se estabelecer comparações do valor encontrado em $x$ (município analisado) e de $m$ (valor mínimo considerado) e $M$ (valor máximo considerado), devem-se coletar dados para as variáveis de um grupo de municípios escolhido. Por exemplo, pode-se comparar a localidade analisada com todos os municípios do Estado, coletando-se os dados de todos os municípios para a construção do índice. Na presente pesquisa, utilizou-se quatro municípios para comparação, que serão apresentados no tópico "área de estudo".

a) Feito o cálculo do índice para cada indicador, é realizada a agregação desses índices por dimensão através da média aritmética, chegando-se ao IDS social, IDS demográfico, IDS econômico, IDS político-institucional, IDS ambiental e IDS cultural do município que será avaliado.

b) Por último O Índice de Desenvolvimento Sustentável (IDS) do município calculado pela média aritmética dos índices de cada dimensão.

Para a representação desses índices referentes a cada variável, ao IDS das dimensões e ao IDS final é utilizado um conjunto de cores que correspondem aos níveis de sustentabilidade. A Tabela 01 mostra a classificação e representação dos índices (variação de 0 e 1), bem como a cor correspondente conforme uma escala definida.

Tabela 01: Classificação e representação dos índices de desenvolvimento sustentável

\begin{tabular}{ccc}
\hline Índice $(0-1)$ & $\begin{array}{c}\text { Nível de } \\
\text { sustentabilidade }\end{array}$ & Coloração \\
\hline $0,7501-1,0000$ & Ideal \\
\hline $0,5001-0,7500$ & Aceitável \\
\hline $0,2501-0,5000$ & Alerta \\
\hline $0,0000-0,2500$ & Crítica & \\
\hline
\end{tabular}

Fonte: Adaptado de Martins e Cândido (2008).

Nessa classificação, os índices de sustentabilidade com valores entre 0,0000 e 0,2500, revelam um nível crítico de sustentabilidade; os índices com valores entre 0,2501 e 0,5000 
demonstram um nível de sustentabilidade em alerta; os índices com valores entre 0,5001 e 0,7500 indicam um nível de sustentabilidade aceitável; e por último, os índices com valores entre 0,7501 e 1,0000 revelam um nível ideal de sustentabilidade.

Destarte, a metodologia englobando todas as dimensões apresentadas (social, demográfica, econômica, político-institucional, ambiental e cultural) foi aplicada no município de Primavera do Leste, utilizando a comparação de dados com outros quatro municípios, conforme será exposto a seguir.

\section{ÁREA DE ESTUDO}

Primavera do Leste é um município do Estado de Mato Grosso - MT (Brasil), localizado na mesorregião do Sudeste Mato-grossense e microrregião de Primavera do Leste. Com uma área territorial de $5472,207 \mathrm{~km}^{2}$, apresenta uma população estimada de 58.370 habitantes (IBGE/2016) e uma densidade de 10,5 hab./ $\mathrm{km}^{2}$. Esse município confronta-se com os municípios de Paranatinga - MT, Santo Antônio do Leste - MT, Poxoréu - MT, Dom Aquino - MT, Campo Verde - MT, Planalto da Serra - MT e Nova Brasilândia - MT.

O Estado de Mato Grosso possui cinco mesorregiões: nordeste, norte, centro-sul, sudoeste e sudeste mato-grossense. Portanto, para comparação de valores e construção dos índices, foram escolhidas outros quatro municípios, pertencentes a cada mesorregião. Essas cidades possuem populações equivalentes, e o motivo da escolha era priorizar uma cidade de cada mesorregião de Mato Grosso, com a mesma população.

As cidades selecionadas conforme esses critérios foram: Lucas do Rio Verde, 59.436 mil habitantes (norte mato-grossense), Poconé, com 32.205 mil habitantes (centro-sul matogrossense), Pontes e Lacerda, com 43.538 mil habitantes (sudoeste mato-grossense) e Barra do Garças, com 58.690 mil habitantes (sudeste mato-grossense) (IBGE/2016). A Figura 01 mostra a localização destas cidades em relação a cada mesorregião.

Figura 01: Localização das sedes municipais em relação às mesorregiões do Estado de Mato Grosso

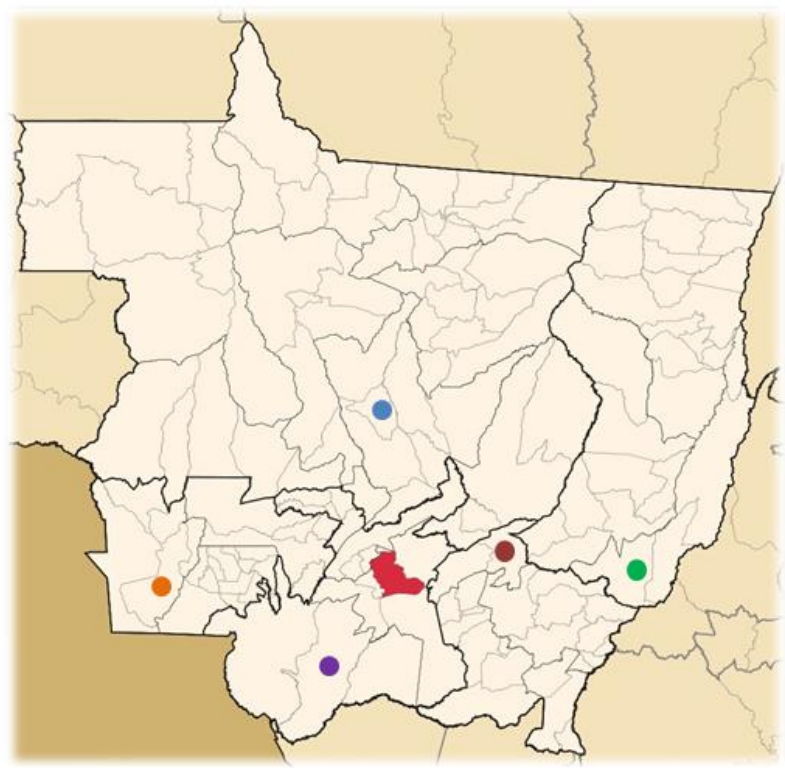

\begin{tabular}{|c|c|}
\hline Cidade & Região \\
\hline Primavera do Leste & Sudeste \\
\hline Lucas do Rio Verde & Norte \\
\hline Poconé & Centro-sul \\
\hline Pontes e Lacerda & Sudoeste \\
\hline Barra do Garças & Nordeste \\
\hline
\end{tabular}

Fonte: as Autoras

Portanto, através da metodologia apresentada, será avaliado o IDSM de Primavera do Leste em comparação com os quatro municípios informados. Sendo que, o critério adotado para 
a escolha desses municípios foram as características semelhantes a Primavera do Leste, dentre eles a quantidade populacional; outrossim, eles pertencem a cada uma das mesorregiões do Estado de Mato Grosso, de forma possibilitar a comparação de dados de diversas localidades.

\section{RESULTADOS E DISCUSSÃO}

A partir da metodologia IDSM, aferiu-se os níveis de sustentabilidade do município de Primavera do Leste, conforme os resultados e a discussão que serão expostos a seguir.

Quanto às dimensões do desenvolvimento sustentável, a primeira dimensão analisada é a social, contemplando temas como saúde, educação, moradia e segurança, dados na Tabela 02.

Tabela 02: Níveis de Sustentabilidade dos Indicadores Sociais de Primavera do Leste.

\section{DIMENSÃO SOCIAL}

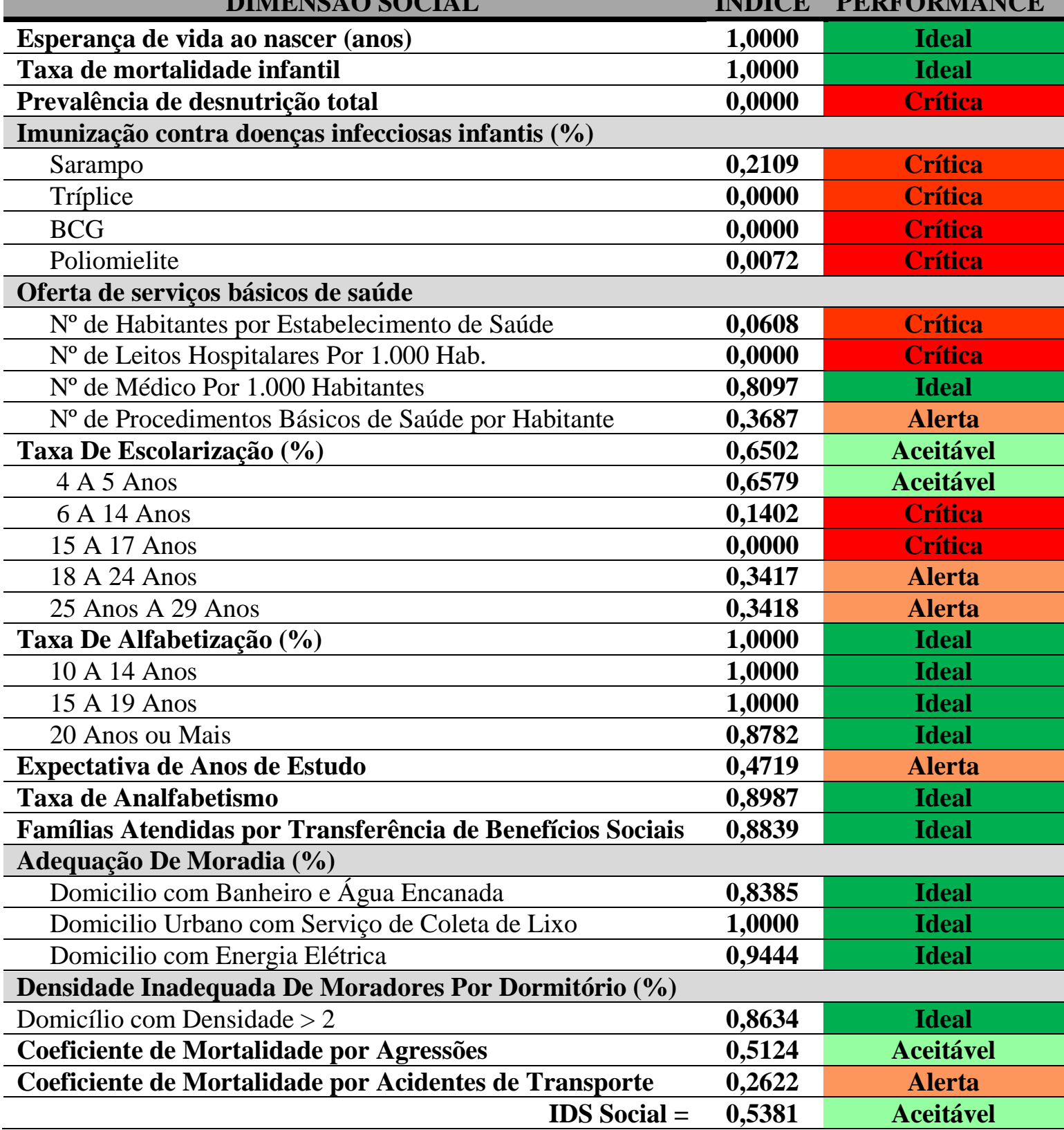

Fonte: Dados da pesquisa

Todos estes indicadores procuram representar uma síntese da situação social e das condições de vida da população. O saldo da Dimensão Social foi positivo, pois seu índice de 
sustentabilidade foi de $\mathbf{0 , 5 3 8 1}$, um nível considerado aceitável, conforme a metodologia e dados da Tabela 02.

A segunda dimensão a ser analisada é a demográfica, que indica o crescimento populacional, a densidade demográfica do município e a relação entre população rural e urbana. Indica também as características da população relacionadas à faixa etária e a razão entre homens e mulheres. Da mesma forma que a dimensão social, Primavera do Leste apresentou um índice de sustentabilidade para a dimensão demográfica em nível de aceitável, com o valor de $\mathbf{0 , 5 8 8 1}$, conforme Tabela 03.

Tabela 03: Níveis de Sustentabilidade dos Indicadores Demográficos de Primavera do Leste

\begin{tabular}{lcc}
\hline \multicolumn{1}{c}{ DIMENSÃO DEMOGRÁFICA } & ÍNDICE & PERFORMANCE \\
\hline Taxa de crescimento da população $(\%)$ & $\mathbf{0 , 0 0 0 0}$ & Crítica \\
\hline Densidade Demográfica $($ hab/km²) & $\mathbf{0 , 7 2 5 2}$ & Aceitável \\
\hline Razão entre a população masculina/feminina & $\mathbf{0 , 3 4 9 5}$ & Alerta \\
\hline Razão entre a população urbana/rural & $\mathbf{1 , 0 0 0 0}$ & Ideal \\
\hline População residente por faixa etária (\%) & & \\
\hline Menor que 1 ano & $\mathbf{0 , 2 8 3 7}$ & Alerta \\
\hline 1 a 4 anos & $\mathbf{0 , 5 7 8 0}$ & Aceitável \\
\hline 5 a 9 anos & $\mathbf{0 , 3 9 8 7}$ & Alerta \\
\hline 10 a 14 anos & $\mathbf{0 , 3 0 7 8}$ & Alerta \\
\hline 15 a 19 anos & $\mathbf{1 , 0 0 0 0}$ & Ideal \\
\hline 20 a 29 anos & $\mathbf{0 , 4 3 4 7}$ & Alerta \\
\hline 30 a 39 anos & $\mathbf{0 , 8 9 7 4}$ & Ideal \\
\hline 40 a 49 anos & $\mathbf{1 , 0 0 0 0}$ & Ideal \\
\hline 50 a 59 anos & $\mathbf{0 , 0 0 0 0}$ & Crítica \\
\hline 60 a 69 anos & $\mathbf{0 , 7 4 5 0}$ & Aceitável \\
\hline 70 a 79 anos & $\mathbf{0 , 7 7 9 8}$ & Ideal \\
\hline 80 anos acima & $\mathbf{0 , 9 0 9 5}$ & Ideal \\
\hline
\end{tabular}

Fonte: Dados da pesquisa

Em relação à característica da população quanto à faixa etária, os baixos índices para população de 50 a 59 anos e a taxa de crescimento da população contribuíram negativamente para o IDS demográfico. Outrossim, apesar das faixas etárias de 20 a 29 estarem com índice desfavorável, as faixas de 30 a 49 anos, que são faixas etárias bem produtivas, encontra-se em um nível ideal.

Os índices que representam a faixa etária de 60 anos acima apresentaram valores satisfatórios. Percebe-se que, por serem indicadores que apresentam uma relação negativa com a sustentabilidade (já que quanto maior a taxa, pior é para a localidade), indicam uma situação aceitável e ideal. Significa dizer que Primavera do Leste não apresenta uma população considerável de idosos. Tal faixa etária tem sua capacidade de produção reduzida, que poderá ensejar gastos públicos na área da saúde, tendo em vista que os atendimentos médicos são mais frequentes na população idosa.

Outros índices também merecem atenção, como a razão entre a população urbana/rural e a densidade demográfica, respectivamente com performances ideal e aceitável. Sobre este último aspecto, ressalta-se que a cidade que Primavera do Leste possui densidade demográfica de 10,67 hab./km² (IBGE/2016). Apesar de ser uma densidade maior que a dos demais municípios analisados, ainda é considerada uma baixa densidade. 
Ressalta-se que a baixa densidade demográfica, aliada a outros fatores como expansão urbana não planejada podem contribuir para que os serviços de infraestrutura urbana se tornem mais ineficientes e onerosos para o poder público. Vale salientar que é importante que o Plano Diretor da cidade seja eficaz e regule o uso do solo, contribuindo para que a densidade demográfica atinja valores mais altos.

A terceira dimensão analisada é a econômica, que trata do desempenho econômico do município, através da balança comercial, PIB per capita e variáveis como renda familiar e índice de Gini, que expressa o grau de concentração da distribuição de renda da população. Nesta dimensão, o índice de sustentabilidade foi de $\mathbf{0 , 8 0 6 5}$, um nível considerado com performance ideal (Tabela 04).

Tabela 04: Níveis de Sustentabilidade dos Indicadores Econômicos de Primavera do Leste

\begin{tabular}{lcc}
\hline \multicolumn{1}{c}{ DIMENSÃO ECONÔMICA } & ÍNDICE & PERFORMANCE \\
\hline Produto interno bruto per capita $(\mathrm{R} \$)$ & $\mathbf{1 , 0 0 0 0}$ & Ideal \\
\hline Participação da indústria no Produto Interno Bruto & $\mathbf{0 , 4 5 5 7}$ & Alerta \\
\hline Índice de Gini da distribuição do rendimento & $\mathbf{0 , 4 4 4 4}$ & Alerta \\
\hline Renda per capita & $\mathbf{1 , 0 0 0 0}$ & Ideal \\
\hline Renda proveniente de rendimentos do trabalho (\%) & $\mathbf{0 , 7 8 8 2}$ & Ideal \\
\hline Renda familiar per capita (\%) & & \\
\hline Até 1/4 (salário mínimo) & $\mathbf{1 , 0 0 0 0}$ & Ideal \\
\hline Mais de 1/4 a 1/2 (salário mínimo) & $\mathbf{0 , 8 3 5 8}$ & Ideal \\
\hline Mais de 1/2 a 1 (salário mínimo) & $\mathbf{0 , 8 5 7 6}$ & Ideal \\
\hline Mais de 1 a 2 (salário mínimo) & $\mathbf{0 , 6 6 1 3}$ & Aceitável \\
\hline Mais de 2 a 3 (salário mínimo) & $\mathbf{0 , 8 7 4 5}$ & Ideal \\
\hline Mais de 3 (salário mínimo) & $\mathbf{0 , 8 7 8 9}$ & Ideal \\
\hline Balança Comercial (US\$) & & \\
\hline Exportações & $\mathbf{0 , 8 0 6 8}$ & Ideal \\
\hline Importações & $\mathbf{0 , 8 6 0 2}$ & Ideal \\
\hline Saldo & $\mathbf{0 , 8 2 8 1}$ & Ideal \\
\hline & $\mathbf{0 , 8 0 6 5}$ & Ideal \\
\hline
\end{tabular}

Fonte: Dados da pesquisa

Verifica-se que, exceto pelos indicadores relacionados à participação da indústria no PIB e o índice de Gini, todos os demais indicadores apresentaram índices elevados, com performances aceitável e ideal. Dessa forma, essa dimensão foi a que apresentou os melhores índices da pesquisa.

A quarta dimensão analisada é a político-institucional, que avalia se o poder público está investindo em setores essenciais que contribuem para a qualidade de vida da população. Verifica também se a população possui a possibilidade de exercer seus direitos e deveres de cidadão.

Mais uma vez, o resultado final da dimensão foi aceitável, apresentando um índice de sustentabilidade no aspecto político-institucional de $\mathbf{0 , 5 7 6 3}$ (Tabela 05). 
Tabela 05: Níveis de Sustentabilidade dos Indicadores Político-Institucionais de Primavera do Leste

\begin{tabular}{lcc}
\hline \multicolumn{1}{c}{ DIMENSÃO POLÍTICO-INSTITUCIONAL } & ÍNDICE & PERFORMANCE \\
\hline Despesas por função (\%) & & \\
\hline Despesas com Ciência e Tecnologia & $\mathbf{0 , 0 0 0 0}$ & Crítica \\
\hline Despesas com Educação & $\mathbf{1 , 0 0 0 0}$ & Ideal \\
\hline Despesas com Cultura & $\mathbf{0 , 0 7 5 2}$ & Crítica \\
\hline Despesas com Assistência Social & $\mathbf{0 , 6 4 5 7}$ & Aceitável \\
\hline Despesas com Desporte e Lazer & $\mathbf{0 , 0 0 1 8}$ & Crítica \\
\hline Despesas com Urbanismo & $\mathbf{0 , 8 4 7 3}$ & Ideal \\
\hline Despesas com Habitação Urbana & $\mathbf{0 , 0 0 0 0}$ & Crítica \\
\hline Despesas com Saneamento Urbano & $\mathbf{0 , 0 0 0 0}$ & Crítica \\
\hline Despesas com Gestão Ambiental & $\mathbf{1 , 0 0 0 0}$ & Ideal \\
\hline Despesa total com saúde por habitante (R\$) & $\mathbf{0 , 9 2 3 2}$ & Ideal \\
\hline Acesso a serviços de Telefonia Fixa & & \\
\hline$N^{\mathbf{o}}$ de acessos individuais & $\mathbf{0 , 4 6 8 9}$ & Alerta \\
\hline \multicolumn{1}{c}{$\mathrm{N}^{\mathbf{0}}$ de acessos públicos } & $\mathbf{1 , 0 0 0 0}$ & Ideal \\
\hline Comparecimento nas eleições & & \\
\hline \multicolumn{1}{c}{ Comparecimento (\%) } & $\mathbf{1 , 0 0 0 0}$ & Ideal \\
\hline Abstenções (\%) & $\mathbf{1 , 0 0 0 0}$ & Ideal \\
\hline Número de Conselhos Municipais & $\mathbf{0 , 6 0 0 0}$ & Aceitável \\
\hline Acesso à justiça & $\mathbf{1 , 0 0 0 0}$ & Ideal \\
\hline Transferências intergovernamentais da União & $\mathbf{0 , 2 3 4 6}$ & Crítica \\
\hline$\quad$ IDS Político-Institucional = & $\mathbf{0 , 5 7 6 3}$ & Aceitável \\
\hline
\end{tabular}

Fonte: Dados da pesquisa

Salienta-se que as despesas relacionadas à Ciência e Tecnologia, Cultura, Desporte e Lazer, Habitação Urbana e Saneamento Urbano apresentaram nível crítico, evidenciando uma carência de investimentos nesses setores.

Dessa forma, verifica-se a necessidade de se repensar as políticas públicas adotadas para esses setores, pois são através desses investimentos e dessas políticas que serão adotadas diretrizes que contribuirão para a sustentabilidade do município.

Outro indicador a ser destacado são as transferências intergovernamentais da união, que por ter uma relação negativa com a sustentabilidade, demonstra que o município teve um dos maiores valor de transferências em relação aos demais municípios analisados.

A penúltima dimensão analisada é a ambiental, que está relacionada ao uso dos recursos naturais, envolvendo análises quanto consumo de água per capita, o nível de qualidade da água e o acesso ao saneamento básico, considerados fundamentais ao benefício das gerações futuras.

Tal dimensão obteve um IDS de $\mathbf{0 , 7 3 4 6}$, e evidenciando uma situação aceitável. Essa situação é justificada pelos vários indicadores que se apresentaram em nível ideal (Tabela 06).

Através do índice apresentado, constata-se que essa dimensão apresentou um resultado aceitável e a população de Primavera do Leste tem acesso satisfatório ao sistema de coleta de resíduos domésticos e boa qualidade da água.

Outro indicador que apresentou desempenho ideal foi o consumo médio per capita de água, que têm relação negativa com a sustentabilidade, sempre que esse consumo é alto. Denota que a população possui um baixo consumo de água, portanto, o dado foi positivo.

No tocante ao tratamento da água, os indicadores relacionados ao acesso do sistema de abastecimento de água e esgotamento sanitário obtiveram níveis críticos e em alerta, o que requer uma maior atenção do poder público local. 
Tabela 06:Níveis de Sustentabilidade dos Indicadores Ambientais de Primavera do Leste

\begin{tabular}{lll}
\hline \multicolumn{1}{c}{ DIMENSÃO AMBIENTAL } & ÍNDICE & PERFORMANCE \\
\hline $\begin{array}{l}\text { Qualidade das águas (\%) } \\
\begin{array}{l}\text { Conformidade na quantidade de amostras analisadas para } \\
\text { aferição de cloro residual }\end{array}\end{array}$ & $\mathbf{1 , 0 0 0 0}$ & Ideal \\
\hline $\begin{array}{l}\text { Incidência de amostras de cloro residual fora do padrão } \\
\text { Conformidade na quantidade de amostras analisadas para }\end{array}$ & $\mathbf{1 , 0 0 0 0}$ & Ideal \\
aferição de turbidez & $\mathbf{1 , 0 0 0 0}$ & Ideal \\
\hline Incidência de amostras com turbidez fora do padrão & $\mathbf{1 , 0 0 0 0}$ & Ideal \\
\hline $\begin{array}{l}\text { Conformidade na quantidade de amostras para identificar } \\
\text { coliformes totais }\end{array}$ & $\mathbf{1 , 0 0 0 0}$ & Ideal \\
\hline $\begin{array}{l}\text { Incidência de amostras com coliformes totais fora do } \\
\text { padrão }\end{array}$ & $\mathbf{1 , 0 0 0 0}$ & Ideal \\
\hline Volume de águas tratada (1000m3/ano) (\%) & & \\
\hline Tratada em ETAs & $\mathbf{0 , 3 1 7 4}$ & Alerta \\
\hline Tratada por desinfecção & $\mathbf{0 , 0 0 0 0}$ & Crítica \\
\hline Consumo médio per capita de água L/(hab*dia) & $\mathbf{0 , 9 9 5 6}$ & Ideal \\
\hline Acesso ao sistema de abastecimento de água (\%) & & \\
\hline Rede geral & $\mathbf{0 , 2 0 2 0}$ & Crítica \\
\hline Poço ou nascente & $\mathbf{0 , 1 6 3 2}$ & Crítica \\
\hline Outro tipo & $\mathbf{0 , 9 8 4 6}$ & Ideal \\
\hline Acesso a esgotamento sanitário (\%) & & \\
\hline Rede geral de esgoto & $\mathbf{0 , 2 8 1 9}$ & Alerta \\
\hline Fossa séptica & $\mathbf{0 , 4 8 1 6}$ & Alerta \\
\hline Outro tipo & $\mathbf{0 , 2 9 4 7}$ & Alerta \\
\hline Não possui esgotamento sanitário & $\mathbf{0 , 9 4 9 8}$ & Ideal \\
\hline Acesso a serviço de coleta de lixo doméstico $(\%)$ & & \\
\hline Lixo coletado & $\mathbf{1 , 0 0 0 0}$ & Ideal \\
\hline Lixo queimado ou enterrado & $\mathbf{1 , 0 0 0 0}$ & Ideal \\
\hline Outro destino & $\mathbf{1 , 0 0 0 0}$ & Ideal \\
\hline & $\mathbf{0 , 7 1 9 5}$ & Aceitável \\
\hline
\end{tabular}

Fonte: Dados da pesquisa

Por fim, a dimensão cultural, identifica a quantidade de equipamentos culturais na cidade, verificando o acesso dos cidadãos ao conhecimento, lazer, entretenimento e cultura.

Em Primavera do Leste, tal dimensão encontra-se em um nível alerta com um IDS de $\mathbf{0 , 4 6 4 3}$, conforme Tabela 07. Portanto, essa dimensão foi a que apresentou os piores resultados em relação às demais dimensões analisadas.

Pelos resultados, percebe-se que em relação a cinemas, teatros e centro cultural, o município apresentou um bom desempenho. Contudo, no tocante a bibliotecas, ginásios, museus e unidades de ensino superior, o desempenho não foi satisfatório, o que contribuiu negativamente para o resultado final da dimensão.

Finalizando as análises de todas as dimensões, têm-se a Tabela 08 que resume os índices de sustentabilidade conforme cada dimensão e apresenta o IDSM da cidade de Primavera do Leste. 
Tabela 07:Níveis de Sustentabilidade dos Indicadores Culturais de Primavera do Leste

\begin{tabular}{lcc}
\hline \multicolumn{1}{c}{ DIMENSÃO CULTURAL } & ÍNDICE & PERFORMANCE \\
\hline Bibliotecas & $\mathbf{0 , 0 0 0 0}$ & Crítica \\
\hline Ginásios de esportes e estádios & $\mathbf{0 , 0 0 0 0}$ & Crítica \\
\hline Cinemas & $\mathbf{1 , 0 0 0 0}$ & Ideal \\
\hline Unidades de ensino superior & $\mathbf{0 , 2 5 0 0}$ & Crítica \\
\hline Teatros ou salas de espetáculos & $\mathbf{1 , 0 0 0 0}$ & Ideal \\
\hline Centro cultural & $\mathbf{1 , 0 0 0 0}$ & Ideal \\
\hline Museus & $\mathbf{0 , 0 0 0 0}$ & Crítica \\
\hline
\end{tabular}

Fonte: Dados da pesquisa

Tabela 08:Índice de Desenvolvimento Sustentável da cidade de Primavera do Leste

\begin{tabular}{|c|c|c|}
\hline DIMENSÕES & ÍNDICE & PERFORMANCE \\
\hline Social & 0,5381 & Aceitável \\
\hline Demográfica & 0,5881 & Aceitável \\
\hline Econômica & 0,8065 & Ideal \\
\hline Político-Institucional & 0,5763 & Aceitável \\
\hline Ambiental & 0,7195 & Aceitável \\
\hline Cultural & 0,4643 & Alerta \\
\hline IDSM= & 0,6155 & Aceitável \\
\hline
\end{tabular}

Fonte: Dados da pesquisa

Verifica-se uma relação favorável no tocante às seis dimensões analisadas, pois nenhuma obteve nível crítico. Veja-se: quatro dimensões apresentam nível "aceitável" (social, demográfica, político-institucional e ambiental), uma dimensão encontra-se em um nível "ideal" (econômica) e uma dimensão em nível de "alerta" (cultural).

Nesse sentido, a partir da média aritmética destas seis dimensões, foi encontrado o IDSM de Primavera do Leste, no valor de $\mathbf{0 , 6 1 5 5}$, um índice com desempenho aceitável. Contudo, nota-se que mesmo que o resultado final não seja crítico, é necessário que políticas públicas sejam implementadas para a manutenção desses níveis, melhorando a qualidade de vida dos munícipes.

\section{CONSIDERAÇÕES FINAIS}

Partindo do pressuposto de que é necessária a utilização de ferramentas eficientes para apontar o caminho a ser percorrido rumo ao desenvolvimento sustentável, a fim de aferir o grau de sustentabilidade do município de Primavera do Leste/MT, optou-se por aplicar neste trabalho a metodologia do IDSM.

Para atingir a finalidade, foram escolhidos para a comparação com Primavera do Leste, dados acerca de outros municípios com características similares dentro de cada mesorregião do Estado de Mato Grosso, e posteriormente foram analisados os respectivos níveis de sustentabilidade social, demográfica, econômica, político-institucional, ambiental e cultural.

Nesse sentido, foi possível demonstrar de forma didática, com a utilização de múltiplas cores nas tabelas que continham dados da pesquisa, que o nível de sustentabilidade de Primavera do Leste apresentou um desempenho aceitável, com IDSM de 0,6155.

Entretanto, notou-se também que esse índice ainda não é o ideal, o que evidencia que é necessária a implementação de políticas públicas principalmente na dimensão cultural, que 
apresentou os menores índices, a fim de elevar o grau de sustentabilidade e propiciar condições adequadas para a qualidade de vida da população atual e das futuras gerações.

Por fim, verifica-se que a metodologia se mostrou eficaz e importantes informações foram colocadas a disposição de todos, em especial do poder público, para que possam implementar ações concentradas nos indicadores que apresentaram níveis mais baixos.

Dessa forma a contribuição do trabalho fomenta o debate sobre a sustentabilidade, que deve sair do plano teórico para o prático, a fim de alcançar uma sociedade mais justa e equilibrada, cooperando, efetivamente, para o desenvolvimento do município e região.

\section{REFERÊNCIAS}

AGÊNCIA NACIONAL DE TELECOMUNICAÇÕES. (Anatel). Sistema de Gestão de Metas de Universalização (SGMU). Disponível em: <http://sistemas.anatel.gov.br/ sgmu/TUP/Lista/frmConsulta.asp?SISQSModulo=17510>. Acesso em: 25 abr. 2014.

ATLAS DE DESENVOLVIMENTO HUMANO NO BRASIL. (IDH). 2013. Disponível em: <http://www.atlasbrasil.org.br/2013/>. Acesso em: 6 maio 2014.

CAIXA ECONÔMICA FEDERAL. (CEF). Consulta pública bolsa família. Disponível em: <https://www.beneficiossociais.caixa.gov.br/consulta/beneficio/04.01.00-00_00. asp>. Acesso em: 26 abr. 2014.

CÂNDIDO, G. A. A Aplicação das dimensões do desenvolvimento sustentável e os níveis da competitividade sistêmica: um estudo comparativo entre regiões produtoras de calçados no Brasil. 2004. Tese (Concurso Professor Titular) - Departamento de Administração e Contabilidade do Centro de Humanidades, Universidade Federal de Campina Grande, Campina Grande, 2004.

CÂNDIDO, G. A.; VASCONCELOS, A. C. F. Índice de desenvolvimento sustentável municipal participativo: uma aplicação no município de cabaceiras - PB. Revista Capital Científico. Guarapuava, v.9, n.2, jul./dez. 2011.

CAVALCANTI, C. Sustentabilidade da Economia: Paradigmas alternativos de realização econômica. In: CAVALCANTI, C. (org.). Desenvolvimento e Natureza: estudo para uma sociedade sustentável. São Paulo: Cortez, 2003.

COMISSÃO MUNDIAL SOBRE MEIO AMBIENTE E DESENVOLVIMENTO (CMMAD). Nosso futuro comum. 2 ed. Rio de Janeiro: Ed. Fundação Getúlio Vargas, 1991.

DEPARTAMENTO DE INFORMÁTICA DO SISTEMA ÚNICO DE SAÚDE DO BRASIL. (Datasus). Caderno de informações de saúde. Disponível em: <http://tabnet.datasus.gov.br/tabdata/cadernos/mt.htm>. Acesso em: 26 abr. 2014.

FINANÇAS DO BRASIL. (Finbra). Disponível em: < http://www.tesouro.fazenda.gov.br/ > Acesso em 27 abr. 2014. 
GUIMARÃES, G. M. A. Agronegócio, desenvolvimento e sustentabilidade: um estudo de caso em Rio Verde - GO. Goiânia. Tese em Ciências Ambientais. Universidade Federal de Goiás. 2010.

INSTITUTO BRASILEIRO DE GEOGRAFIA E ESTATÍSTICA. (IBGE). Indicadores de desenvolvimento sustentável: Brasil 2012. Diretoria de Geociências (Estudos e Pesquisas). Rio de Janeiro: IBGE, 2012.

Censo demográfico 2010 e estimativa populacional 2016: resultados da amostra. Disponível em: <http://www.cidades.ibge.gov.br/>. Acesso em: 25 abr. 2014.

Perfil dos municípios brasileiros - gestão pública 2010. Disponível em: <http://munic.ibge.gov.br/index.php?ano=2012>. Acesso em: 25 maio 2014.

MARTINS, M. F.; CÂNDIDO, G. A. Índice de desenvolvimento sustentável para municípios (IDSM): metodologia para análise e cálculo do IDSM e classificação dos níveis de sustentabilidade, uma aplicação no Estado da Paraíba. João Pessoa: Sebrae, 2008.

SANTOS, J. G.; CÂNDIDO, G. A. A Sustentabilidade da Agricultura Orgânica Familiar dos Produtores Vinculados a Associação de Desenvolvimento Econômico, Social e Comunitário (ADESC) de Lagoa Seca - PB. In: Anais do Encontro Nacional da Anppas, 5., 2010, Florianópolis. Anais...Florianópolis: ANPPAS, 2010.

SECRETARIA DO COMÉRCIO EXTERIOR. (SECEX). Balança comercial brasileira por município. Disponível em: <http://www.mdic.gov.br/sitio/sistema/balanca/> Acesso em: 01 mai. 2014.

SICHE, R.; AGOSTINHO, F.; ORTEGA, E.; ROMEIRO, A. Índices versus indicadores: precisões conceituais na discussão da sustentabilidade de países. Ambiente e Sociedade. Campinas, v.10, n.2, jul/dez.2007.

SISTEMA NACIONAL DE INFORMAÇÕES SOBRE SANEAMENTO. (SNIS). Abastecimento de água. Disponível em: <http://www.snis.gov.br/PaginaCarrega.php?EWRErterterTERTer=6 >. Acesso em: 01 mai. 2014.

TRIBUNAL SUPERIOR ELEITORAL. (TSE). Estatísticas e resultados da eleição - quadro de comparecimento. Disponível em: <http://www.tse.jus.br/hotSites/estatistica2012/quadrocomparecimento.html $>$. Acesso em: 02 de mai. 2014.

VAN BELLEN, H. M. Indicadores de sustentabilidade: uma análise comparativa. Rio de Janeiro: Ed. FGV, 2005. 